\title{
Social capital of older adults in the urban city of Valparaiso
}

\begin{abstract}
Introduction: Social capital is an import asset in the context of healthy and active ageing. Bridging social capital refers to the networks that tie people from different social groups; in contrast, bonding social capital implies the existence of intimate ties, based on trust.

Objective: To measure the social capital of older adults, user of the public primary health care.

Methods: Descriptive study, implemented in a non-experimental design, carried out in the city of Valparaiso, Chile with a sample of 146 subjects.

Results: The data allows to indicate that older adults have more bonding capital than bridging capital. Moreover, it was observed that older people with higher levels of education present higher mean scores of social capital, result that is related to social status, availability of social resources and healthier ageing.

Conclusion: The knowledge of the nature and size of social networks from the perspective of bonding and bridging social capital in older people will allow comprehending the importance for the better opportunities the access to institutional resources for to have the right to healthier aging.
\end{abstract}

Keywords: older adults, social capital, primary health care
Volume 2 Issue 2 - 2017

\author{
Arcos E,' Bailey C, ${ }^{2}$ Sánchez $X,{ }^{2}$ González L ${ }^{3}$ \\ 'Nursing Faculty, Universidad Andrés Bello, Chile \\ ${ }^{2}$ Social Sciences Faculty, Universidad de Playa Ancha, Chile \\ ${ }^{3}$ Doctoral Program, Universidad Andrés Bello, Chile
}

Correspondence: Estela Arcos, Nursing Faculty, Universidad Andrés Bello, Chile,Tel 56-9-88842964,Email marcos@unab.cl

Received: August 27, 2017| Published: September 08, 2017

\section{Introduction}

Background information indicates that by the year 2020, older population in Chile will be of 3.2 million the persons. ${ }^{1}$ Authors say that because of this population increase it is important to carry out investigations that focalize not only in studies of morbidity, risk factors and disease prevalence in older adults, but specially orientated to the consideration of healthy and positive ageing because it implicates subjective well-being which is associated with a better quality of life. ${ }^{2}$

The concept of social capital is relatively new in the field of social epidemiology and health behavior, however there are studies that state its value in health research ${ }^{3}$ because the empirical evidence of the relationship between social capital and health outcomes. Social isolation has been related to health disorders, especially in older adults. ${ }^{4}$ It was been reported that broad social networks favor a healthier ageing process, thus reducing the incidence of stress and depressive symptoms. ${ }^{5}$ In regards of the above, the objective of this study was to measure social capital of older adults, user of the public primary health care.

\section{Material and method}

This investigation corresponds to descriptive study, implemented in a non-experimental design, carried out in the urban city of Valparaiso, Chile. The universe was 233 older adults' active, autonomous, between the age of 64, and 83 years, users of a primary health center in Valparaiso. An aleatory sample with a confidence of $95 \%$ and a $5 \%$ error and the final estimated sample size was 146 . The technique used was the social survey. A structure survey questionnaire with close-ended questions allowed to measure a set of sociodemographic variables and the level of social capital in older adults from Chen's
Social Capital Scale ${ }^{3,6}$ which through 10 items measures bonding and bridging social capital. The first five items of the scale measured bonding social capital and the other five bridging social capital. The questionnaire was pretested in a different population to assess validity. Reliability was confirmed using the Cronbach's Alpha coefficient $(0.870)$. The participation of the older adults was voluntary and informed, with a signed informed consent form. A previously trained graduate student in the home of the older adult applied the survey. Statistical analysis was performed using SPSS, v. 22. Data analysis was carried out using descriptive statistics such as distribution, central tendency (mean score) and dispersion (standard deviation). Inferential statistics procedures were used to compare results between groups (Student's t- distribution) and to correlate variables (Spearman correlation). The Scientific Ethics Committee, Nursing Faculty, Universidad Andrés Bello authorized the study, LI/CECENF/62.

\section{Results and discussion}

The main results show that the mean age of the subjects was $73 \pm 4.9$ years, with a $77.4 \%$ of women in the sample. $56.9 \%$ had high school education; $75.3 \%$ were catholic and $53.5 \%$ single. $17.8 \%$ stated to have no living offspring and $41.7 \%$ have at least 1 living son or daughter. In regards to territorial roots, it was observed that $52.0 \%$ had lived 57 or more years in the neighborhood and only $21.2 \%$ participated in social organizations for the elderly.

The five first items of Chen's scale measure bonding social capital and the rest measure bridging social capital. Bonding social capital refers to intimate - generally familiar - ties, based on trust, bridging social capital link people from different social - formal and informal - groups. 
Comparatively, the data allows to point out that older adults have more bonding than bridging social capital. The respondents perceived little power and prestige among their contacts and weak participation in social organizations, of which they feel they are not represented Table 1.

Table I Descriptive statistics for ítems of bonding social capital and bridging social capital of I 46 older adults of Valparaíso, Chile

\begin{tabular}{|c|c|c|c|c|}
\hline Social capital scale & Mín. & Max. & Mean score & Sd \\
\hline \multicolumn{5}{|l|}{ Union social capital } \\
\hline $\begin{array}{l}\text { Item I: Number of friends } \\
\text { and family members }\end{array}$ & I & 5 & 3.093 & 0.9694 \\
\hline Item 2: Routine contact & I & 4.75 & 3.248 & 0.7809 \\
\hline $\begin{array}{l}\text { Item } 3: \text { Trust in family and } \\
\text { friends }\end{array}$ & I & 4 & 2.582 & 0.7023 \\
\hline $\begin{array}{l}\text { Item 4: Help from family } \\
\text { and friends }\end{array}$ & I & 4.5 & 2.822 & 0.913 \\
\hline $\begin{array}{l}\text { Item 5: Power and prestige } \\
\text { of contacts }\end{array}$ & I & 3.67 & 2.529 & 0.5776 \\
\hline \multicolumn{5}{|l|}{ Bridging social capital } \\
\hline $\begin{array}{l}\text { Item 6: Number of } \\
\text { organizations }\end{array}$ & 1 & 5 & 2.654 & 0.9183 \\
\hline Item 7: Participation & I & 4 & 1.514 & 0.7449 \\
\hline Item 8: Representation & I & 5 & 1.527 & 0.7895 \\
\hline $\begin{array}{l}\text { Item 9: Help from } \\
\text { organizations }\end{array}$ & 1 & 5 & 2.253 & 0.8852 \\
\hline $\begin{array}{l}\text { Item I0: Prestige and } \\
\text { power of organizations }\end{array}$ & I & 4 & 2.435 & 0.7824 \\
\hline
\end{tabular}

$\mathrm{N}=46$ for all variables, mean scores were calculated on a I to 5 score scale

The correlational analysis with scores obtained in the measurement of bonding and bridging social capital and sociodemographic variables showed that age increases, less bonding capital is observed, as shown in Table 2. Although a negative correlation between age and bridging social capital is also observed, such correlation is not statistically significant. It can be hypothesized that a reason why bonding capital decreases as age increases could be related to the progressive loss of family members due to their emancipation from their families homes. In a cultural context where the traditional nuclear family pattern is an important referent, it could be possible that older adults could find themselves in lonely situations in terms of maintaining intimate family ties. When observing the variable number of living offspring, it is possible to relate it to a higher bridging social capital. It can be presumed that a higher number of offspring benefits older adults in terms of their connection to resources outside the family environment. The support that older adults can receive, during difficult times, is likely to come from agencies, institutions, and organizations outside the family group. This makes sense when considering the characteristics of the group of older adults in the study, which live in a context of social vulnerability and therefore, is probable that their families maintain a similar socioeconomics profile.

Another variable that presented a positive association with both bonding and bridging capital was the level of education. This is coherent with literature, because education is one of the main assets of social capital ${ }^{8}$ to mobilize support networks. Older adults with higher years of formal education tend to have better health outcome because, among other reasons, they are better informed and have better access to better healthcare services. ${ }^{9}$

Table 2 Correlation between bonding and bridging social capital and sociodemographic variables

\begin{tabular}{llllll}
\hline \multirow{2}{*}{ Variables } & \multicolumn{2}{l}{$\begin{array}{l}\text { Bonding social } \\
\text { capital }\end{array}$} & \multicolumn{3}{l}{$\begin{array}{l}\text { Bridging social } \\
\text { capital }\end{array}$} \\
\cline { 5 - 6 } & $\mathbf{R}$ & $\mathbf{P}$ & $\mathbf{R}$ & $\begin{array}{l}\mathbf{P} \\
\text { value }\end{array}$ \\
\hline Age & $-0.310^{* *}$ & 0 & -0.079 & 0.342 \\
Education & $0.207^{*}$ & 0.012 & $0.319^{* *}$ & 0.000 \\
Living offspring & $0.170^{*}$ & 0.04 & $0.264^{* *}$ & 0.001 \\
Territorial roots & -0.115 & 0.17 & $0.263^{* *}$ & 0.001 \\
\hline
\end{tabular}

$\mathrm{n}=\mid 46 * *$ Correlation is significant at the 0.01 level. * Correlation is significant at the 0.05 level

To contrast the difference between social capital scores and categorical variables an independent group t-test for difference in means was used, as shown in Table 3 . In regards to religion, it is observed that Christian evangelicals present higher scores of bonding social capital than catholics and this difference is statistically significant. On the other hand, older adults also present significant differences when comparing their marital status, where married older adults have higher bridging social capital. Lastly, in regards to senior adult's clubs, it is observed that those who take part of a club show higher scores of bridging social capital, which can serve to hypothesized that these organizations could be a mechanism to contact networks that, in other circunstances, they would have no access to.

Table 3 Independent group t-test between social nominal variables and social capital

\begin{tabular}{|c|c|c|c|c|c|c|c|c|c|}
\hline \multirow[b]{2}{*}{ Variables } & \multirow[b]{2}{*}{ Categories } & \multicolumn{4}{|c|}{ Bonding social capital } & \multicolumn{4}{|c|}{ Bridging social capital } \\
\hline & & Mean Score & $\mathbf{t}$ & df & P value & Mean Score & $\mathbf{t}$ & Df & $P$ value \\
\hline \multirow[t]{2}{*}{ Religion } & Catholic & 2.565 & -2.947 & 143 & 0.004 & 2.1279 & -1.386 & 143 & 0.168 \\
\hline & Evangelical & 2.8431 & & & & 2.288 & & & \\
\hline Marital status & Single & 2.5865 & -1.42 & 144 & 0.158 & 2.0328 & -2.914 & 144 & 0.004 \\
\hline \multirow[t]{2}{*}{$\begin{array}{l}\text { Participation on senior } \\
\text { adult clubs }\end{array}$} & Yes & 2.6794 & 0.532 & 144 & 0.596 & 2.4971 & 3.656 & 144 & 0 \\
\hline & No & 2.6278 & & & & 2.0738 & & & \\
\hline
\end{tabular}




\section{Conclusión}

The interaction with stable social networks is associated with a better use of available resources in society as well as better wellbeing, better health mental status and higher resilience, that is, a healthier aging. ${ }^{10-12}$ On the other hand, the people with low socioeconomic level have less social capital and loneliness, is associated with mental health morbidity. ${ }^{13}$ The knowledge of the nature and size of social networks from the perspective of bonding and bridging social capital in older people will allow comprehending the importance for the better opportunities the access to institutional resources for to have the right to healthier aging. ${ }^{13-15}$

\section{Acknowledgements}

The Scientific Ethics Committee, Nursing Faculty, Universidad Andrés Bello authorized the study, LI/CECENF/62.

The research project was fully sponsored by Playa Ancha University with grant number CDUPA 1301. In case of no financial assistance for the research work, provide the information regarding the sponsor.

\section{Conflict of interest}

Authors declare there is no conflict of interest in composing this manuscript.

\section{References}

1. Mac-CO, Barozet E, Maturana V. Desigualdad, clase media y territorio en Chile: clase media global o múltiples mesocracias según territorios?. EURE (Santiago). 2014;40(121):163-183.

2. Dijk H, Cramm J, Birnie E, et al. Effects of an integrated neighborhood approach on older people's (health-related) quality of life and wellbeing. BMC Research Notes. 2016;9(1):450.

3. Chen X, Stanton B, Li X, et al. Personal Social Capital Scale: An instrument for health and behavioral research. Health Education Research. 2009;24(2):306-317.

4. Hawton A, Green C, Dickens A, et al. The impact of social isolation on the health status and health-related quality of life of older people. Quality Of Life Research. 2011;20(1):57-67.
5. Berglund $\mathrm{H}$, Hasson $\mathrm{H}$, Wilhelmson $\mathrm{K}$, et al. The impact of socioeconomic conditions, social networks, and health on frail older people's life satisfaction: a cross-sectional study. Health Psychology Research. 2016;4(1):26-31.

6. Arcos E, Sánchez X, Bailey C, et al. Capital social de las mujeres mayores usuarias de la red pública de la Atención Primaria de Salud. Revista médica de Chile. 2016;144(8):972-979.

7. Kirkby GE, King N, Bravington A. Social Capital and Community Group Participation: Examining 'Bridging' and 'Bonding' in the Context of a Healthy Living Centre in the UK. Journal Of Community \& Applied Social Psychology. 2013;23(4):271-285.

8. Jandaghi G, Haghgooyan Z, Mashayekhi M. Studying the Association between Social Capital and Educations in Qom Tax Organization. European Researcher. 2014;77(6-2):1133-1141.

9. Younsi M, Chakroun M. Does social capital determine health? Empirical evidence from MENA countries. Social Science Journal. 2016;53(3):371-379.

10. Cornwell B, Laumann E. The health benefits of network growth: New evidence from a national survey of older adults. Soc Sci Med. 2015;125:94-106.

11. Waverijn,G, Wolfe M, Mohnen S, et al. A prospective analysis of the effect of neighbourhood and individual social capital on changes in self-rated health of people with chronic illness. BMC Public Health. 2014;14(1):675-685.

12. Murayama H, Nofuji Y, Matsuo E, et al. Are neighborhood bonding and bridging social capital protective against depressive mood in old age? A multilevel analysis in Japan. Soc Sci Med. 2015;124:171-179.

13. Nyqvist F, Victor C, Forsman A, et al. The association between social capital and loneliness in different age groups: a population-based study in Western Finland. BMC Public Health. 2016;16(1):1-8.

14. Uphoff E, Pickett K, Cabieses B, et al. A systematic review of the relationships between social capital and socioeconomic inequalities in health: a contribution to understanding the psychosocial pathway of health inequalities. Int $J$ Equity Health. 2013;12(1):54-65.

15. Taylor R. Networking in primary health care: how connections can increase social capital. Primary Health Care. 2013;23(10):34-40. 